\title{
Health professionals' beliefs about domestic abuse and the issue of disclosure: a critical incident technique study
}

\author{
Julie Taylor RN MSc PhD ${ }^{1}$, Caroline Bradbury-Jones RN HV PhD ${ }^{2}$, Thilo Kroll PhD Dipl-Psych (GER) ${ }^{3}$ and Fiona \\ Duncan RN HV BA ${ }^{4}$ \\ ${ }^{1}$ NSPCC Child Protection Research Centre, University of Edinburgh, Edinburgh, UK, ${ }^{2}$ School of Nursing and Midwifery, \\ University of Dundee Scotland, Dundee, UK, ${ }^{3}$ Social Dimensions of Health Institute, Universities of Dundee and St \\ Andrews, Dundee, UK and ${ }^{4}$ National Health Service (NHS) Cardenden Fife, UK
}

Accepted for publication 21 January 2013

\author{
Correspondence \\ Julie Taylor \\ NSPCC Child Protection Research \\ Centre \\ University of Edinburgh \\ Moray House, \\ 3.15 St Leonard's Land \\ Holyrood Road, \\ Edinburgh EH8 8AQ, UK \\ E-mail: julie.taylor@ed.ac.uk
}

\section{What is known about this topic}

- Domestic abuse is a serious public health issue.

- Women who experience domestic abuse often conceal their experiences.

- Health professionals' responses to domestic abuse are sometimes inadequate.

\section{What this paper adds}

- Health professionals and abused women do not always share the same beliefs about domestic abuse.

- Discussing abuse with women is something that health professionals find difficult, but women want to be asked.

- Several practices can be adopted by health professionals to keep women safe post-disclosure, including 'code talk'.

\begin{abstract}
Domestic abuse is increasingly recognised as a serious, worldwide public health concern. There is a significant body of literature regarding domestic abuse, but little is known about health professionals' beliefs about domestic abuse disclosure. In addition, the intersection between health professionals' beliefs and abused women's views remains uninvestigated. We report on a two-phase, qualitative study using Critical Incident Technique (CIT) that aimed to explore community health professionals' beliefs about domestic abuse and the issue of disclosure. We investigated this from the perspectives of both health professionals and abused women. The study took place in Scotland during 2011. The study was informed theoretically by the Common Sense Model of Self-Regulation of Health and Illness (CSM). This model is typically used in disease-orientated research. In our innovative use, however, CSM was used to study the social phenomenon, domestic abuse. The study involved semi-structured, individual CIT interviews with health professionals and focus groups with women who had experienced domestic abuse. Twenty-nine health professionals (Midwives, Health Visitors and General Practitioners) participated in the first phase of the study. In the second phase, three focus groups were conducted with a total of 14 women. Data were analysed using a combination of an inductive classification and framework analysis. Findings highlight the points of convergence and divergence between abused women's and health professionals' beliefs about abuse. Although there was some agreement, they do not always share the same views. For example, women want to be asked about abuse, but many health professionals do not feel confident or comfortable discussing the issue. Overall, the study shows the dynamic interaction between women's and health professionals' beliefs about domestic abuse and readiness to discuss and respond to it. Understanding these complex dynamics assists in the employment of appropriate strategies to support women post-disclosure.
\end{abstract}

Keywords: commonsense model, critical incident technique, disclosure, domestic abuse, intimate partner violence, routine enquiry
Domestic abuse is a common cause of: physical injury (Campbell 2002); depression and alcohol/drug misuse (Lazenbatt et al. 2009); and suicide (World Health Organization 2005). In its most extreme form, vio- lence kills women. In the United Kingdom, two women are killed every week by a current or former partner (Hester 2009). We acknowledge that domestic abuse can take place against men by women (Flinck 
\& Paavilainen 2010), or within same-sex relationships, but $90 \%$ of domestic abuse is committed by men against women (Department of Health 2005). For this reason, our research was concentrated on women survivors. Nonetheless we agree there is further important work to be done with men who are abused (World Health Organization 2012).

Domestic abuse affects the entire family unit, including children. Between 55\% (Hester 2009) and $90 \%$ of domestic abuse occurs when children are present, or nearby (Department of Health 2005). Domestic abuse has serious, negative consequences on children's health and well-being. Children living with domestic abuse are likely to suffer depression and anxiety; behavioural problems and developmental delay. At its worst, domestic abuse is associated with mortality in children under 5 years (Department of Health 2005). Overall, domestic abuse has serious consequences for women and children to the extent that it is recognised as a major public health concern (Peckover 2003, Department of Health 2005, Humphreys et al. 2008, McGarry et al. 2011).

Increasing recognition of the short and longer term consequences of domestic abuse has led to a mounting body of empirical evidence regarding the issue. It is known, for example, that abused women are reluctant to disclose abuse (Peckover 2003, Feder et al. 2009, Spangaro et al. 2011), yet they still want the issue to be discussed (Bacchus et al. 2002, Koziol-McLain et al. 2008). There is also evidence regarding health professionals' reluctance in this area (Montalvo-Leindo 2008, Lazenbatt \& Thompson-Cree 2009). Relatively little, however, is known about health professionals' beliefs about domestic abuse and disclosure more generally. In addition, the intersection between health professionals' beliefs and abused women's views remains under-investigated. Yet understanding these issues is important if appropriate, supportive strategies are to be adopted by health professionals to support abused women.
We report on a qualitative study that used Critical Incident Technique (CIT) to explore health professionals' beliefs about domestic abuse and the issue of disclosure. We investigated this from the perspectives of health professionals and abused women. The study was theoretically informed by the Common Sense Model (CSM) of self-regulation of health and illness (Leventhal et al. 2003), which has been used to explore the links between cognitive illness representations and health behaviours. Central to this model is representations - or beliefs - about illness. Leventhal and colleagues describe five elements of such representations: identity (the label or name given to a condition); cause (ideas about perceived causes of a condition); timeline (beliefs about how long the condition will last); consequences (perceptions regarding the consequences and impact of a condition); and curability/controllability (beliefs about the extent to which a condition can be cured or controlled). CSM is typically used in disease-/condition-orientated research relating to how people's beliefs influence their behaviour.

In our innovative use, we used it to inform our understanding of how health professionals' beliefs about the identity and controllability of domestic abuse shape their approaches and responses to domestic abuse. CSM can be tracked through our research design and was used, for example, to organise the interview schedule and the analysis process. As far as we are aware, CSM has not previously been applied to domestic abuse. As a model to understand 'illness behaviours', we could not apply it to the present study without modification. We moulded it to fit the unique needs of our study. Table 1 illustrates how we operationalised the CSM alongside the original meaning.

We wanted to explore the utility of this health psychology model to explore the relationship between the health professionals' beliefs about domestic abuse as a 'chronic condition' and how these align with the perspectives of abused women. Our intention was to answer the following questions:

- What are health professionals' beliefs about the nature and consequences of domestic abuse?

Table 1 Interpretation of Common Sense Model applied in this study

\begin{tabular}{|c|c|c|}
\hline Domain & Original understandings & Interpretations in this study \\
\hline Identity & The label given to a condition & Identification and recognition of domestic abuse \\
\hline Cause & Ideas about perceived causes & The context in which domestic abuse occurs \\
\hline Timeline & Beliefs about how long the condition will last & $\begin{array}{l}\text { Temporal aspects of domestic abuse, such as the 'right time' } \\
\text { for routine enquiry and disclosure }\end{array}$ \\
\hline Curability/controllability & $\begin{array}{l}\text { Beliefs about the extent to which a } \\
\text { condition can be cured }\end{array}$ & $\begin{array}{l}\text { Where the responsibility lies for disclosure } \\
\text { and subsequent response }\end{array}$ \\
\hline Consequences & $\begin{array}{l}\text { Perceptions regarding the } \\
\text { consequences and impact of a condition }\end{array}$ & $\begin{array}{l}\text { Consequences of domestic abuse for women; their children } \\
\text { and health professionals }\end{array}$ \\
\hline
\end{tabular}


- In what ways might health professionals' beliefs about domestic abuse shape their practices regarding enquiring and responding to domestic abuse?

- What are the views of women with domestic abuse experiences about health professionals' beliefs about disclosure?

\section{Methods}

We used a two-phase study design comprising interviews with health professionals (phase one) and focus groups with women survivors of domestic abuse (phase two). Individual, CIT interviews were used to capture the experiences of health professionals, from which we designed a series of vignettes to use in focus groups with the women. CIT was originally developed by Flanagan (1954) as part of his involvement with the Aviation Psychology Program of the United States Army Air Force. During this time a series of CIT studies was used to improve the outcome of flying missions. The hallmark of a CIT study is a focus on 'real' events, rather than abstract concepts. It typically involves asking respondents to recount actual incidents. We were interested in how health professionals' beliefs shaped their actual practices regarding domestic abuse, therefore, critical incident technique was congruent with the study aim and with the underpinning theoretical framework (CSM). Data generation took place between May and September 2011 by the same two members of the research team throughout (CBJ, FD). All interviews and focus groups were recorded and transcribed verbatim.

\section{Phase one: health professionals' perspectives}

\section{Participants}

Twenty-nine health professionals were recruited from two health boards (regions) in Scotland using purposive sampling [midwives $n=11$; health visitors (public health nurses) $n=16$; general practitioners/family physicians $n=2$ ]. To be included, participants needed to have current or recent experience of working in a community setting and practice experience of responding to domestic abuse.

\section{Data generation}

A unique feature of CIT is a focus on the number of incidents collected, rather than the number of participants (Bradbury-Jones \& Tranter 2008). This is an important distinction because the 29 participants who participated in the first phase of our study recalled a total of 101 critical incidents, thus generating abundant data. The semi-structured nature of the inter-
Table 2 Prompt interview questions corresponding to Common Sense Model

- Tell me about an incident where you have responded to domestic abuse.

-What led you to suspect/identify the abuse? What prompted you to respond? (identity)

- What might have been the reasons for the abuse in the incident you describe? (cause)

- How long had the abuse been happening? (timeline)

-What impact do you think the abuse had on the woman? Why did you respond in the way you describe? What were the consequences of this response?' (consequences)

-What has happened to the woman since the incident? What to you imagine are her long-term prospects? On reflection how do you feel about the way the incident was managed? (curability/control)

views meant that we were able to frame our questions in a manner that aligned with CSM (Table 2). Participants were asked to recall two incidents from practice where a woman had disclosed domestic abuse.

\section{Data analysis}

Data were analysed using a combination of an inductive classification system designed specifically for CIT (Cormack 2000) and framework analysis (Ritchie \& encer 1994). The framework approach involves the process of sifting, charting and sorting data into key areas. We chose it because it balances structure with the ability to generate inductively derived categories. Initial analysis highlighted 11 categories. These and their respective sub-categories were then mapped against the five CSM domains (Table 3). In the results section midwives are denoted MW; health visitors HV and general practitioners GP. To enhance reliability, analysis was undertaken independently by two research team members (CBJ, JT) and emerging categories were discussed among the whole team and revised until consensus was achieved. Finally, selected critical incidents were transformed into anonymised 'vignettes' for use in phase two (Table 4). We purposefully selected vignettes from across the three different professional groups. In addition, we sought to capture different health professionals' beliefs about domestic abuse, for example, whether a direct approach (vignette 1) or an 'open door' (vignette 4) is most appropriate.

\section{Phase two: women's perspectives}

Participants

Women who had experienced domestic abuse were recruited via the non-statutory organisation, Scottish 
Table 3 Inductively derived categories mapped against the commonsense model domains

\begin{tabular}{|c|c|c|c|}
\hline $\begin{array}{l}\text { Commonsense } \\
\text { Model domain }\end{array}$ & Category & Sub-category & Citations \\
\hline \multirow[t]{6}{*}{ Identity } & \multirow[t]{4}{*}{ Types of abuse } & Sexual & 4 \\
\hline & & Financial & 8 \\
\hline & & Emotional & 23 \\
\hline & & Physical & 27 \\
\hline & \multirow[t]{2}{*}{ Sociocultural bias } & Ethnicity & 3 \\
\hline & & Social class & 5 \\
\hline \multirow[t]{6}{*}{ Cause } & \multirow[t]{5}{*}{ Associated factors/context } & Alcohol use & 7 \\
\hline & & Social isolation & 13 \\
\hline & & Drug use & 15 \\
\hline & & Mental health & 17 \\
\hline & & Pregnancy & 17 \\
\hline & Self-inflicted & Women's fault & 7 \\
\hline \multirow[t]{5}{*}{ Timeline } & \multirow[t]{3}{*}{ Disclosure readiness } & Disclosure as a discrete event & 11 \\
\hline & & Previous concealment & 14 \\
\hline & & Disclosure as a process & 17 \\
\hline & \multirow[t]{2}{*}{ Manifestation/nature of abuse } & Abuse as a one-off event & 5 \\
\hline & & Abuse as a chronic state & 25 \\
\hline \multirow[t]{2}{*}{ Curability } & \multirow[t]{2}{*}{ Locus of control } & Health professional & 6 \\
\hline & & Woman & 13 \\
\hline \multirow{9}{*}{ Consequences } & \multirow[t]{2}{*}{ Severity of abuse } & Abuse as a life-threatening event & 11 \\
\hline & & Long-term impact on health & 11 \\
\hline & \multirow[t]{2}{*}{ Consequences for women } & Homelessness & 13 \\
\hline & & Stay with perpetrator & 11 \\
\hline & \multirow{2}{*}{ Consequences for children } & Unsafe & 2 \\
\hline & & Protected & 9 \\
\hline & \multirow[t]{3}{*}{ Consequences for health professionals } & Shock at woman's choice & 9 \\
\hline & & Hopelessness & 11 \\
\hline & & Frustration/concern & 14 \\
\hline
\end{tabular}

Women's Aid, using purposive sampling. Scottish Women's Aid is the lead organisation in Scotland to tackle violence against women, and to campaign for and provide services addressing the needs of women who have experienced domestic abuse. To take part the women must have experienced domestic abuse and disclosed this to a health professional. We facilitated three focus group interviews with a total of 14 women, comprising: Group $1 n=4$; Group $2 n=7$; Group $3 n=3$. Two of these groups were with all white women and one with all Asian women.

\section{Data generation}

Each group was presented orally with three vignettes and the women were invited to explore health professionals' decisions and responses in relation to domestic abuse. Women appeared to enjoy listening to and responding to the vignettes and lively discussion and debate was generated.

Data analysis

Data analysis and reliability checks described in phase one were mirrored in this second phase of the study. Thus, similarly, data were mapped against the five CSM domains (Table 3). In the results section quotations from the focus groups are denoted FG.

\section{Ethics}

Ethical approval was granted via the NHS National Patient Safety Agency Research Ethics Service (East of Scotland REC, ref 10/S1402/49). Spangaro et al. (2011) have drawn attention to the ethical issues of conducting research regarding domestic abuse. Specifically, they highlighted the challenges of maximising participation and addressing safety. In our study, we strived towards ensuring participation and voice of abused women by means of an advisory panel that was consulted at all stages of the study from inception through to conclusion. Regarding safety, we perceived this as operating at different levels, with responsibility as a research team to keep women physically and emotionally safe. To ensure this we adopted several strategies. All focus group interviews were conducted in Women's Aid centres which provided a safe physical environment for the women and one with which they were familiar. No demo- 
Table 4 Example vignettes constructed from phase one interviews, used in phase two focus groups

Vignette 1: l've been working as a midwife for many years and I routinely ask pregnant women about domestic abuse. I'll say 'Now, I hope you don't mind, but we like to see all pregnant ladies on their own, to ask about domestic abuse' I explain that pregnant women are at greater risk of domestic abuse and we want to be able to offer support and help if that is the case. Most women say they don't mind being asked. One very young girl said she was too scared to go home to her partner and asked me to help her find somewhere else to stay. We managed to arrange for a support worker to come and help her to find temporary accommodation and then the Family health midwife got involved to give additional support until her baby was born and for a couple of months after.

Vignette 2: I've visited one woman recently and she had a black eye, but totally denied that it was her partner and that's a very difficult one because I know there is domestic abuse there and she is not willing to discuss it ... it is really difficult because even if you actually see a mark, they deny it. It's really difficult to help. You can give information but it's up to the woman to decide to seek help but sometimes, for whatever reason, you know, they're too frightened or they just don't want to leave the situation because they believe the situation would be worse if they left.

Vignette 3: There was a family that I knew quite well and I had no inkling that there were any issues surrounding domestic abuse. But 1 day she came to an immunisation clinic for immunisations and she just burst into tears and said 'I can't go home' and that's when I explored the thing ... I had known the family for a year before that and I had no idea that there were any issues. I saw them quite regularly because they were quite vulnerable and I knew that they had dabbled in drugs and things but when she did disclose it opened a whole can of worms, there was serious drug abuse, there'd been long term domestic abuse and he had assaulted her during pregnancy and things like this and it was really quite severe. And I felt terrible because I should have picked up on this, through my relationship with them but she disclosed and we had then to decide what to do.

Vignette 4: It's her choice at the end of the day. All I can do as the GP is, you know, because she's seeing me anyway for Methadone, is you need to be there, be supportive, just watch out for other bits and pieces that might come up that you can see like change of mood, how things are getting on and help with that as it appears and kind of leave that door open for her to be able to come back.

graphic data were collected from them in a bid to protect their anonymity.

Regarding data generation, using vignettes to prompt discussion meant that emphasis was removed from women's own abusive experiences. Vignettes that focus on the actions of others provide a safe, supportive space for discussion (Bradbury-Jones et al. 2012). The research design allowed women to discuss the issue of domestic abuse in a manner that focused on other people, rather than themselves. We felt this was an important protective element of the study for this group of potentially vulnerable women. How- ever, our previous experience of research with abused women has shown that most are keen to discuss the issue from their own perspective. Indeed, the focus groups were highly interactive: women were forthcoming, sharing their experiences with humour and supporting each other.

One participant explained that her primary reason for participating in the study was so that her experiences could be heard. The study had thus been a mechanism through which women could exercise voice. In terms of ongoing support, all women had close contact with a Women's Aid worker, and in addition, we provided helpline numbers for protection services, in case these were required.

Full signed and informed consent was gained from all participants following distribution of participant information sheets (slightly different versions for health professionals and women in the focus groups). We were careful to anonymise data and where these might have been attributable (e.g. by gender or by particular event) they were either disguised or omitted.

Finally, as a research team we were mindful of the need to support one another while studying this sensitive issue. Many of the accounts - particularly those from the abused women - were harrowing and to varying degrees each of us were affected emotionally. Team debrief, mutual support and openness with each other, helped ameliorate the potentially distressing effects of undertaking the study.

\section{Findings}

Findings from both phases are presented in juxtaposition to show points of convergence and divergence between health professionals' and women's perspectives. We use the CSM domains to structure the results.

\section{Identity}

In the context of this study, the CSM domain of identity was interpreted as the identification and recognition of domestic abuse (Table 1). Physical abuse was the most frequent form of abuse recalled by health professionals $(n=27)$, and emotional abuse was similarly highly cited $(n=23)$. Irrespective of the type of abuse, some health professionals believed that on occasions, they recognise abuse even when women themselves do not identify that they are being abused:

He had punched holes in the walls ... in the doors, he was shouting at her, he was berating her, he was swearing at 
her in front of the kids. She didn't see that as emotional abuse. HV1

The health professional perspectives converge with those of women, who reported that they often fail to identify their own experiences as abusive:

You are going down and down and you don't even know that you are being abused. FG1

The problem with lack of recognition of abuse among women is that it hampers disclosure. This was expressed simply by a participant in the first focus group:

See if you didn't know that you are being abused you cannot tell somebody that you are being abused. FG1

In this study, we were interested in beliefs about who - and specifically which groups of people - are likely to experience domestic abuse. One health professional stated:

We are all aware that it's women from right across the social strata that are victims of domestic abuse. The wife of the bank manager and the lawyer might be able to hide it better. He maybe has the sense to know where to batter black and blue as opposed to the wife of the chappie [man] who's maybe not so bright and you know just batters her anyway. MW2

Despite that, some health professionals believed that it is easier to broach the subject of domestic abuse with some people more than others:

I think actually the middle-classes are harder to ask because ... I think the women in a lower socio-economic class don't care that you've asked. MW5

Women too had much to say about biases associated with domestic abuse, but they were clear that there should be no difference between groups:

[There should be no difference between] Joe Bloggs and Dr Double-Barrelled Name. FG2

Health professionals have to deal with anyone who is experiencing domestic abuse, everybody irrespective of their race, their culture, their tradition, their sexuality, it should not matter. They should feel equipped enough to address it. FG3

\section{Cause}

There are no simple, linear causes of domestic abuse, but there are a number of well-documented risk factors that create a context in which abuse can flourish. In this study, as indicated in Table 1, 'cause' is thus interpreted more broadly than in the Common Sense Model conceptualisation by Leventhal and colleagues and relates to the context in which domestic abuse occurs and the factors associated with it. Table 4 illustrates how many health professionals in this study recognised the complexity of factors associated with domestic abuse, particularly mental health issues $(n=17)$ and pregnancy $(n=17)$ :

Some of them it's not just domestic abuse that's an issue there's a million and one other issues. Some of them have got huge social issues. MW10

Health professionals believed it was incumbent upon them to identify these associations:

They come in with physical things or generally kind of depression kind of things and you have to tease out this is what's going on underneath. GP1

We were surprised to find that seven health professionals believed that women themselves had a role in the onset of domestic abuse in that they either chose the wrong partners or contributed to a domestic atmosphere of tension and violence.

She just unfortunately makes a bad choice in men. HV1

She didn't seem to mind that he pushed her about a bit. HV7

This finding highlighted an interesting divergence because although some health professionals hold this belief, many women consider that health professionals go to great length to absolve them of responsibility for the abuse:

She [health visitor] said 'You are not the one that is wrong, you are the right one, you are the one that is getting it done to you'. FG1

\section{Timeline}

In the context of this study, the CSM domain of timeline refers to beliefs regarding issues of a temporal nature (Table 1). A key finding regarding timeline relates to disclosure. Eleven health professionals recounted incidents where women had disclosed domestic abuse at one specific point in time - this was usually associated with a crisis point and escalation of violence. However, most health professionals believed that disclosure is a process that happens over time, rather than a discrete event $(n=17)$. Associated with this are beliefs about the propensity of women to conceal abuse $(n=14)$. On the issue of reluctance towards disclosure, there was convergence of views. Women also highlighted the likelihood to deny abuse:

But even when I went to the hospital ... He was in the waiting room, saying, if you say anything, I'll kill you. The doctor said, how did this happen? I said, I fell off my bike. He said, well, you're not wearing a crash helmet. I felt like 
saying, I should have been wearing armour because of what I'll get when I get home. FG2

Women in the focus group discussed the importance of continuity in relationships as a facilitator to disclosure:

I think seeing the same person more than twice is important; getting a relationship with the person and a trust there. You're more likely to say aye, okay, I'll speak about this and I'm going to be alright. FG1

\section{Curability}

There is no cure for domestic abuse. The CSM 'curability' domain in this study is concerned with health professionals' beliefs about where the responsibility lies regarding disclosure. Several health professionals cited that the responsibility for asking about domestic abuse lay with them. Part of this responsibility related to asking women about abuse. However, in this, some health professionals were concerned about loss of control:

You feel that you're going to be opening up a can of worms and you're not equipped to deal with whatever those worms are. It's the scary feeling of not being in control of what you're going to be able to do for that woman. MW4

As a point of divergence, however, women stated clearly that health professionals have a responsibility to ask about abuse. Moreover, they want to be asked:

If they come to you and they think you are being abused and you're not, what harm is done? Nay! FG1

They're used to dealing with bad news or difficult subjects, difficult situations. So what is their issue? What's their problem? FG2

\section{Consequences}

There are a number of serious consequences of domestic abuse. Eleven health professionals referred to the enduring health consequences for women and their children. Many more cited the social consequences of abuse. Almost half $(n=13)$ cited the issue of homelessness as a serious consequence for women (and their children), for example:

[The women said] 'What do I do'? If I go to a refuge then my children have to move school and all that ... I lose my house, I lose being near to family support, I lose all of that. Why should I do that, when it's his fault? HV15

Similarly, a woman recalled:

I walked away with nothing at all ... I had no place to sleep I had nothing and I had a week until they said there is a place for me. FG1
In terms of health, the long-term emotional trauma of abuse was captured by one woman:

He [ex-partner as perpetrator] passed me and I thought I could deal with it. My stomach was going like mad. I wanted to go to the toilet to be sick. I couldn't breathe. It's horrible. I don't know what it is ... I still go into the house sometimes and I look behind me. FG2

A number of women talked about long-term use of antidepressants and an apparent reluctance among health professionals to address the root cause:

I went to my doctor, and it was, 'here's anti-depressants sweetheart', and I said, 'no, I know what's wrong'. FG1

He was giving me diazepam, temazepam, every kind on pam! FG1

Overall, the consequences for women can be summed up thus:

Your life's destroyed. FG2

A number of health professionals were aware of the consequences of domestic abuse on children. However, some believed that in the absence of physical violence, children were likely to be 'okay':

The kids were okay, one was a baby anyway but the toddler seemed to be okay. I don't think, even now, she's never said that he hit the children. HV2

In the same way as women sometimes fail to recognise that they are being abused, health professionals believed that women sometimes fail to see the effects of abuse on their children:

What we often hear is: 'My partner wouldn't harm the baby' and even when you categorically state to them 'That may be the case but they can be accidentally harmed and then there's the emotional impact. You cannot spare the child or the baby from that'. HV12

Finally, in terms of consequences for health professionals, supporting women through domestic abuse experiences involves significant emotional labour:

She graphically described the rape to me, how he removed the stitches, how he held her down and how he repeatedly done these things in front of her child. So it affects us as well. And in a way you're being very sensitive but you've still to be very professional and you have to show empathy without the tears. MW1

Because most health professionals in the study believed that domestic abuse has serious consequences, in the face of disclosure most health professionals took appropriate action:

I gave her the numbers of Women's Aid and I said contact them every day. HV14 
Table 5 Converging and diverging perspectives of health professionals and women

\section{Converging perspectives}

Women often fail to recognise the abusive nature of a relationship and need help to identify their experiences as abuse.

Women are likely to deny abuse.

Health professionals have a responsibility to ask about abuse, but women need to be prepared to disclose.

Domestic abuse has serious, long-term health and social consequences.

\section{Diverging perspectives}

Health professionals are concerned about domestic abuse enquiry, but women want to be asked.

Health professionals find it more difficult to broach the subject of abuse with certain groups, but women expect that they all be treated equally.

Some health professionals believe that women are complicit in their own abuse, but abused women feel absolved of responsibility for the abuse.

I received a hysterical phone call ... she was hysterical and screaming on the phone. So I had dropped what I was doing that minute and I went out ... The social services were contacted and the police were called. MW9

They devised subtle strategies for seeing women and talking to them about their abuse in a manner that kept them safe:

I have to visit when he's not there. So I just phone her up and see if he's there and I mean had he been there I would have said I was doing a pre-school visit. HV9

One woman highlighted a helpful strategy that she had negotiated with her health visitor as a means of keeping her safe post-disclosure. She called it 'code talk':

On the phone she uses code talk. [She says] Is something happening at home? 'Yes'. 'Are you able to talk?' 'No'. 'Will I phone you back tomorrow?' 'Yes'. He doesn't know what she's asking. He doesn't have a clue that you're saying 'well actually yes, something is happening'. But if he heard me saying 'well this has happened. I'm really frightened'. He's going to go mental. Code talk is the answer. FG 1

However, amidst the largely helpful responses by health professionals reported by women, there was one stark account of lack of action by a district nurse:

The district nurse was terrible, absolutely terrible ... He [partner] was pushing me around when the district nurse was there ... I said to the district nurse, 'his temper is getting worse and worse as the time's going on here. What do I do?' She just goes, well, if it gets out of hand, just call the police ... She saw what my husband did to me and she just backed straight off from it and she was in there ... She saw my husband pushing me around and she just stood there like a numpty. FG2

\section{Discussion}

This study canvassed the perspectives of health professionals and women who have experienced domestic abuse. Although there were considerable shared understandings, there were also some points of divergence. These indicated in Table 5 and are captured in the ensuing discussion.

A study in South Africa highlighted the fact that nurses as people experience the same cultural values and similar levels of violence as the clients they are expected to support, thus internalising dominant cultural values and beliefs regarding gender-based violence (Kim \& Motsei 2002). The CSM domain of identity in our study revealed some fascinating insights regarding such beliefs. There was recognition among health professionals that abuse is experienced in all sectors of society. It appears somewhat contradictory, however, that although they recognised that abuse crosses social strata, some found it easier to broach the subject of domestic abuse with women from certain groups, than others. This was a perspective that was not welcomed by the abused women in the study, who voiced a desire for all women to be treated equally. Disappointingly, there was evidence that some health professionals believed that women were complicit in their own abuse, either through their behaviour or through choice. Again, this aligns with findings from other studies (Sugg et al. 1999, Lazenbatt et al. 2005, Peters 2008, Thapar-Bjorkert \& Morgan 2010). Overall, it appears that negative myths and stereotypes continue to be endorsed by society (Lazenbatt et al. 2005).

Regarding the CSM domains of timeline and curability, our findings concur with earlier research in that women are likely to conceal abuse. Reasons for this include shame (Montalvo-Leindo 2008, Feder et al. 2009), fear of further abuse and fear of having their children 'taken away' (Spangaro et al. 2011). In recognition of the difficulty that women face in disclosing abuse, routine enquiry (whereby a standard question is asked at any health assessment) has been widely advocated (Bacchus et al. 2002, Feder et al. 2009, 2011, Lazenbatt \& Thompson-Cree 2009). Yet studies have highlighted health professionals' reluctance to address the issue of abuse with women (Gerbert et al. 2002, Lazenbatt et al. 2005, Salmon et al. 2006, Peters 2008, Lazenbatt \& Thompson-Cree 2009). This was reflected in our findings too. As our data show, health professionals may not probe for disclo- 
sure if they do not have evidence of physical child abuse. They may delay a more systematic enquiry if they believe that changing the status quo will have adverse consequences for the families' children. However, as a point of convergence we found that women want to be asked about abuse. Again, this concurs with earlier research. Robinson \& Spilsbury (2008) highlighted that women would be embarrassed to raise the subject with a GP, but they would like GPs to initiate a discussion about the issue. In a large systematic review, most women find screening acceptable (Feder et al. 2009) and in a sample population of $718,99 \%$ women found it acceptable to be asked about domestic abuse (Bacchus et al. 2002). Likewise a qualitative study undertaken in New Zealand found that women were not offended when asked about abuse (Koziol-McLain et al. 2008). Interestingly, women without a history of violence cautioned that intimate partner violence screening might be offensive to those who are abused, whereas those who reported abuse thought screening was essential to stop it from happening (Koziol-McLain et al. 2008). There has been discussion in the literature about the consequences of 'medicalisation of domestic abuse' for the women experiencing it, highlighting the tendency to individualise the problem with a primary focus on physical and emotional symptoms and in contributing to their victimisation rather than the social structure and dynamic processes that are involved (Lavis et al. 2005). In terms of responses, previous research has identified variations in individual midwives' responses post-disclosure, including non-response (ignoring the disclosure) (Lazenbatt et al. 2009). In our study, many health professionals had taken decisive, supportive action following a woman's disclosure. However, the harrowing account of one woman who had been abused in front of a health professional who ignored the abuse is, by any judgement, an incredulous response. Fortunately, however, this type of account was unusual and extreme. Overall, our findings show that because health professionals believe domestic abuse to be a serious issue with long-term consequences for health and social well-being, most had developed sophisticated techniques to support abused women, including adopting 'code talk'. This provides new evidence for the strategies that abused women find helpful.

\section{Limitations of the study}

Four main limitations were identified. In Phase 1, we had planned to attract an evenly balanced sample of midwives, general practitioners and health visitors (10 in each group). However, we did not recruit as many GPs as intended - a not unusual phenomenon (Williamson et al. 2007), but nonetheless disappointing. To compensate for under-recruitment of GPs, we exercised flexibility and over-recruited to the other professional groups. This limitation means that study findings need to be interpreted cautiously regarding pertinence to general practitioner practice. Second, in phase two, focus group participants had already disclosed domestic abuse to health professionals. Recruiting women who had not disclosed, or who had disclosed but were not part of a group such as Women's Aid would have offered further perspectives. Third, regarding theory, although CSM was useful in organising our findings, we interpreted some representations more broadly than Leventhal might suggest. Some may see this as bastardisation of the model's origins. Further criticism may be directed towards the use of this model in terms of its risk of individualising the issue of domestic abuse. As a psychological model it very much focuses on individual perspectives at the expense of structural and social process factors. Finally, this qualitative study was undertaken in one region of Scotland. Although not a limitation in itself, this calls for critical reflection during interpretation and transferability of findings to different contexts and countries.

\section{Conclusion}

In terms of theory, the Common Sense Model worked well as a tool for uncovering healthcare professionals' beliefs about domestic abuse. Its different components have given shape to our new understandings regarding how they identify abuse, its associations (causes) with other factors and consequences for themselves, women and children. This is the first time that CSM has been used to explore beliefs in relation to a social phenomenon such as domestic abuse. The innovative usage has potential to understand a plethora of phenomena relevant to health and social care contexts. We suggest it as a useful theoretical framework for other researchers. Further research needs to examine more closely the links between a specific set of beliefs and the intention to act. Moreover, a greater focus on the health-professionalwoman dyad could produce interesting findings that account more for the interaction over time and in specific situations. Understanding this process better may help to address issues of miscommunications that prevent early disclosure.

In providing new research evidence, our findings highlight the points of convergence and divergence between abused women's and health professionals' beliefs about abuse. Although there was some agree- 
ment, they do not always share the same views. Overall, the study shows the dynamic interaction between women's and health professionals' beliefs about domestic abuse and readiness to discuss and respond to it. Understanding these complex dynamics assists in the employment of appropriate strategies to support women post-disclosure.

\section{Funding}

The authors disclosed receipt of the following financial support for the research, authorship and/or publication of this article: Chief Scientist Office, Scottish Government. Ref: CZB/2/492.

\section{Conflict of interest}

The authors declared no conflicts of interest with respect to the research, authorship and/or publication of this article.

\section{References}

Bacchus L., Mezey G. \& Bewley S. (2002) Women's perceptions and experiences of routine enquiry for domestic violence in a maternity service. International Journal of Obstetrics and Gynaecology 109, 9-16.

Bradbury-Jones C. \& Tranter S. (2008) Inconsistent use of the Critical Incident Technique in nursing research. Journal of Advanced Nursing 64, 399-407.

Bradbury-Jones C., Taylor J. \& Herber O. (2012) Vignette development and administration: a framework for protecting research participants. International Journal of Social Research Methodology. Available at: http://dx.doi.org/10.1080/ 13645579.2012.750833 (accessed on 27/2/2013).

Campbell J.C. (2002) Health consequences of intimate partner violence. Lancet 359, 1331-1336.

Cormack D. (2000) The Research Process in Nursing. Blackwell Science, Oxford, UK.

Department of Health (2005) Responding to Domestic Abuse: A Handbook for Health Professionals. Department of Health, London, UK.

Feder G., Ramsay J., Dunne D. et al. (2009) How far does screening women for domestic (partner) violence in different health-care settings meet criteria for a screening programme? Systematic reviews of nine UK National Screening Committee criteria. Health Technology Assessment 13, 1-1136.

Feder G., Davies R.A., Baird K. et al. (2011) Identification and referral to improve safety (IRIS) of women experiencing domestic violence with a primary care training and support programme: a cluster randomised controlled trial. The Lancet 378, 1788-1795.

Flanagan J. (1954) The critical incident technique. Psychological Bulletin 51, 327-358.

Flinck A. \& Paavilainen E. (2010) Women's experiences of their violent behavior in an intimate partner relationship. Qualitative Health Research 20, 306-318.

Gerbert B., Gansky S. \& Tang J. (2002) Domestic violence compared to other health risks: a survey of physicians' beliefs and behaviors. American Journal of Preventive Medicine 23, 82-90.

Global Network of Women's Shelters (2012) 2011 Global Shelter Count. Available at: http://www.gnws.org/en/work/ global-data-count/2011-global-shelter-data-count.html (accessed on 5/4/2012)

Hester M. (2009) Who Does What to Whom?. Univ. of Bristol/Northern Rock Foundation, Bristol, UK.

Home Office (2012) Cross Government Definition of Domestic Violence - A Consultation Summary of Responses. Available at: http://www.homeoffice.gov.uk/publications/aboutus/consultations/definition-domestic-violence/domesticviolence-definition (accessed on 10/10/2012)

Humphreys C., Houghton C. \& Ellis J. (2008) Literature Review: Better Outcomes for Children and Young People Experiencing Domestic Abuse. Scottish Government, Edinburgh, UK.

Kim J. \& Motsei M. (2002) 'Women enjoy punishment': attitudes and experiences of gender-based violence among PHC nurses in rural South Africa. Social Science \& Medicine 54, 1243-1254.

Koziol-McLain J., Giddings L., Rameka M. \& Fyfe E. (2008) Intimate partner violence screening and brief intervention: experiences of women in two New Zealand health care settings. Journal of Midwifery $\mathcal{E}$ Women's Health 53, 504510.

Lavis V., Horrocks C., Kelly N. \& Barker V. (2005) Domestic violence: opening Pandora's box. Challenges and dilemmas. Feminism and Psychology 15, 441-460.

Lazenbatt A. \& Thompson-Cree M.E.M. (2009) Recognizing the co-occurrence of domestic and child abuse: a comparison of community- and hospital-based midwives. Health and Social Care in the Community 17, 358-370.

Lazenbatt A., Thompson-Cree M.E.M. \& McMurray F. (2005) The use of exploratory factor analysis in evaluating midwives' attitudes and stereotypical myths related to the identification and management of domestic violence in practice. Midwifery 21, 322-334.

Lazenbatt A., Taylor J. \& Cree L. (2009) A healthy settings framework: an evaluation and comparison of midwives' responses to addressing domestic violence. Midwifery 25, 622-636.

Leventhal H., Brissette I. \& Leventhal E.A. (2003) The Common-Sense Model of self-regulation of health and illness. In: L.D. Cameron and H. Leventhal (Eds) The Self-Regulation of Health and Illness Behaviour, pp. 42-61. Routledge, London, UK.

McGarry J., Simpson C. \& Hinchliff-Smith K. (2011) The impact of domestic abuse for older women: a review of the literature. Health and Social Care in the Community 19, 3-14.

Montalvo-Leindo N. (2008) Cross-cultural factors in disclosure of intimate partner violence: an integrated review. Journal of Advanced Nursing 65, 20-34.

Peckover S. (2003) 'I could have just done with a little more help': an analysis of women's help-seeking from health visitors in the context of domestic violence. Health and Social Care in the Community 11, 275-282.

Peters J. (2008) Domestic violence myths. In: J. Keeling \& T. Mason (Eds) Domestic Violence: A Multi-professional Approach for Healthcare Practitioners, pp. 139-148. Open University Press, Maidenhead, UK.

Ritchie J. \& Spencer L. (1994) Qualitative data analysis for applied policy research. In: A. Bryman and R. Burgess 
(Eds) Analysing Qualitative Data, pp. 173-194. Routledge, London, UK.

Robinson L. \& Spilsbury K. (2008) Systematic review of the perceptions and experiences of accessing health services by adult victims of domestic violence. Health and Social Care in the Community 16, 16-30.

Salmon D., Murphy S., Baird K. \& Price S. (2006) An evaluation of the effectiveness of an educational programme promoting the introduction of routine antenatal enquiry for domestic violence. Midwifery 22, 6-14.

Scottish Government (2008) Gender-based Violence Action Plan. Scottish Government, Edinburgh, UK.

Spangaro J., Poulos R. \& Zwi A. (2011) Pandora doesn't live here anymore: normalization of screening for intimate partner violence in Australian antenatal, mental health and substance abuse services. Violence and Victims 26, 130-144.
Sugg N., Thompson R., Thompson D., Maiuro R. \& Rivara F. (1999) Domestic violence and primary care: attitudes, practices and beliefs. Archives of Family Medicine 8, 301-330.

Thapar-Bjorkert S. \& Morgan K. (2010) 'But sometimes I think ... they put themselves in the situation': exploring blame and responsibility in interpersonal violence. Violence Against Women 16, 32-35.

Williamson M., Pirkis J., Pfaff J.J. et al. (2007) Recruiting and retaining GPs and patients in intervention studies: the DEPS-GP project as a case study. BMC Medical Research Methodology 7, 1-9.

World Health Organization (2005) WHO Multi-country Study on Women's Health and Domestic Violence Against Women. WHO, Geneva, Switzerland.

World Health Organization (2012) Multi-Country Study on Women's Health and Domestic Violence Against Women. World Health Organization, Geneva, Switzerland. 